\title{
ARTIGO
}

\section{O profissional da informação no mundo do trabalho e as relações de gênero}

\author{
The information professional in the work \\ place and the gender relations
}

Maria Mary FERREIRA ${ }^{1}$

\section{RE S U M O}

Este artigo aborda o papel da mulher no mundo do trabalho, tendo como principal enfoque as profissões ditas femininas. Procurou-se dar ênfase ao / à profissional da informação, bem como aos condicionantes que demarcam a escolha dessa profissão, a partir da perspectiva de gênero. Considera-se que trabalhar a questão de gênero significa redimensionar o papel da bibliotecária, contribuindo para uma revisão crítica de seu trabalho.

Palavras-chave: gênero, Biblioteconomia, mulher, trabalho, profissão feminina.

\section{A B S T R A C T}

This study considers the role of women in the work place and the so-called women's professions. It focuses on the Information Science professionals and discusses, from the gender perspective, the conditions that drive the individual to choose a profession in the field. Discussing the gender issues, in this case, means to reevaluate the role of the woman Librarian, thus contributing to a critical review of her work so far.

Key words: workplace and gender, Information Science professionals, woman Librarian, women's profession.

\footnotetext{
1 Professora do Departamento de Biblioteconomia, Universidade Federal do Maranhão, Mestre em Políticas Públicas/UFMA, doutoranda em Sociologia UNESP/Fclar.

Recebido e aceito para publicação em 8/7/2003.
} 


\section{N T R O D U Ç Ã O}

A inserção da mulher no mundo do trabalho é cada vez mais visível. Dados do IBGE, por exemplo, apontam que $40,3 \%$ do mercado está sob sua responsabilidade. A maior parte desse mercado, entretanto, está nas chamadas profissões femininas, consideradas como tal pela proporção de mulheres em seus quadros (LEGISLATIVO, 2002, p.6). Dentre essas profissões podemos citar as empregadas domésticas, secretárias, professoras, assistentes sociais, enfermeiras e bibliotecárias, que são objeto desse nosso estudo. É certo que nas últimas décadas houve uma mudança acentuada no que se refere à busca de mulheres e homens por áreas antes "interditadas" ao sexo oposto (NASCIMENTO et al., 1997), entretanto o que predomina em algumas dessas profissões citadas é um universo quase que exclusivamente feminino. Se antes isso era visto como um fato natural, dada à condição do ser feminino, a partir dos anos setenta, os estudos sobre mulher $e$ gênero vêm mostrar que existia nesta escolha questões que passavam despercebidas, dadas as relações de gênero que, tanto quanto as relações de classe e etnia, mascaram valores e transformam questões políticas, naturalizando-as.

Os estudos sobre a mulher e as relações de gênero evoluíram significativamente nos vários centros de pesquisa do País, trazendo como filosofia novas interpretações da realidade, fazendo vir à tona contradições antes despercebidas. Sua interlocução direta com o movimento feminista possibilitou um amadurecimento teórico-político, que tem contribuído para uma intervenção mais qualificada desse movimento. Esses estudos passaram a constituir-se como tal na década de setenta, quando pesquisadoras feministas romperam com modelos tradicionais de pesquisa e passaram a estudar a mulher enquanto sujeito.

As metodologias até então utilizadas eram incompatíveis para estudar a mulher, não conseguindo satisfazer as pesquisadoras, uma vez que se caracterizavam pelo estudo do diferente; assim, determinadas particularidades só foram percebidas quando pesquisadoras feministas puderam captar e ao mesmo tempo confrontá-las com estudos já consolidados como verdades, nos quais as mulheres estavam ausentes ou eram representadas de forma pejorativa, mais ligadas às atividades de reprodução, contribuindo, dessa forma, com a construção de uma imagem negativa em relação a mulher, o que prevalece até os dias atuais.

$\mathrm{Na}$ Biblioteconomia, estudos com enfoque de gênero ainda não estão consolidados, à exceção de alguns artigos especializados na área, que, em geral, não aprofundam as questões de gênero na profissão do/a bibliotecário/a.

A dificuldade de abordagem dessa temática na Biblioteconomia e na Ciência da Informação constitui um problema que só será equacionado com a revisão do seu ensino e a busca de uma práxis social, que assuma um caráter revolucionário - transformador da realidade - no sentido de repensar o trabalho feminino nessas áreas, buscando as causas de sua desvalorização e apontando saídas para que a profissional da informação reavalie sua inserção no mundo do trabalho e os conflitos advindos das relações sociais e de gênero. Para tanto, há que se repensar e que se rever os valores, cujo percurso passa pela reconstituição histórica do curso de Biblioteconomia no Brasil e pela correlação de forças que foram estabelecidas para a sua inserção nas chamadas profissões de cunho liberal e na consciência de que as relações de gênero, por serem hierarquizadas, é que tem colocado as mulheres em situação de desprestígio social, principalmente naquelas profissões onde há o predomínio do sexo feminino.

Neste estudo, propomos uma discussão a partir de três pontos: no primeiro, abordamos o gênero como tema de pesquisa no Brasil, partindo da sua trajetória, conceituando o termo 
e mostrando sua importância para uma reflexão sobre a mulher. No segundo, fazemos algumas reflexões sobre a mulher no mundo do trabalho, privilegiando a profissão do/a bibliotecário/a, sob a perspectiva de gênero. Justificamos a importância e a necessidade de uma análise de gênero na Biblioteconomia, como forma de repensar o papel feminino e de como estes estudos poderão ser importantes para uma revisão do papel do/a profissional da informação enquanto sujeito. Finalmente, no último ponto apresentamos algumas análises que poderão suscitar o debate e despertar o interesse dos/as leitores/as pela temática.

\section{GÊNERO COMO TEMA DE PESQUISA NO BRASIL}

A razão e a imparcialidade foram sem dúvida pontos norteadores da ciência moderna, entretanto foi em nome da chamada racionalidade que a ciência dicotomizou o ser humano desvalorizando-o em sua plenitude, negando sua emoção, sentimentos, paixões. "A clivagem deu-se, tanto no plano individual quanto no social, na medida em que essas características são atravessadas pela questão de gênero, no que diz ser a razão um atributo masculino [e a emoção] e o sentimento, feminino" (PASSOS, 2001, p.22). O gênero, como categoria analítica, é um modo de referir-se a organização social das relações entre os sexos. Ele busca explicações para a discriminação da mulher, sujeita aos papéis que as inferiorizam baseando-se em sua função reprodutiva ou na força física do sexo masculino. Por ser relacional, a categoria gênero rejeita conceitos que separam os sexos entre si. A partir da visão de gênero, os estudos deixam de ser estudos isolados para serem estudos de relações entre homens e mulheres. "O conceito de relações de gênero deve ser capaz de captar a trama de relações sociais" (SAFFIOTI, 1994, p. 187), bem como os processos de transformações de que as mulheres têm sido alvo ou sujeito ao longo da história.
Construído simbolicamente, o gênero tem uma configuração histórica e uma dimensão universal, que faz parte do ser humano tanto quanto o nascimento e a morte; significa "pensar as diferenças entre mulheres e homens no singular e no plural, intramulheres e intra-homens, colocando, portanto, ambas universalidades e particularidades em questão" (MACHADO, 1992, p.31). Os estudos sobre gênero, e anteriormente, os estudos sobre a mulher trabalharam sempre numa perspectiva de "superação das desigualdades, entre indivíduos socialmente discriminados" (BRUSCHINI, 1992, p.290). O seu discurso, tanto quanto sua prática, a exemplo do movimento feminista, traz em sua filosofia a superação dessas desigualdades, em uma perspectiva transformadora, redimensionando o espaço público (político) e o privado (doméstico).

Desde a Antigüidade, as mulheres estiveram sempre limitadas aos espaços domésticos, isto porque no privado estavam confinados os seres sem poder - os não cidadãos (as mulheres, os escravos). No espaço público estavam os outros seres, aqueles que exerciam o poder de mando, e de ação, no caso, os homens. Para Arendt (1981, p.62) "O termo público significa o próprio mundo, na medida em que é comum a todos nós e diferente do lugar que nos cabe dentro dele". Entretanto, esse mundo não é igual a terra, a natureza; ele é visto como espaço limitado para o movimento dos homens e da condição geral da vida orgânica. $O$ fato de as mulheres serem milenarmente consideradas como coisas da terra e da natureza foi uma maneira de excluí-las dos espaços de decisão ou desvalorizar aquilo que era de seu domínio. O exemplo mais significativo foi a perseguição às mulheres na idade média - que, ao praticarem a medicina a partir de um conhecimento empírico da natureza foram exterminadas como bruxas.

Embora a distinção entre o público e o privado coincida com a oposição entre a necessidade e a liberdade, entre a futilidade e a realização e, finalmente, entre a vergonha e a 
honra, não é de forma alguma verdadeira que somente o necessário, o fútil e o vergonhoso tenham o seu lugar adequado na esfera privada. O significado mais elementar das duas esferas indica que há coisas que devem ser ocultadas e outras que necessitam ser expostas em público para que possam adquirir alguma forma de existência (ARENDT, 1981, p. 84).

A necessidade de politizar o privado redimensionando-o tem sido a forma de valorizar o feminino, descortinando questões até então despercebidas, que com os estudos de gênero passaram a ser vistas por uma nova dimensão.

Estudos sobre a condição feminina não são nenhuma novidade hoje, uma vez que as mulheres foram lembradas por Engels, Marx, Freud e Darwin. O novo, segundo Bruschini (1992) está no exame das relações de gênero e a busca de uma resposta para a opressão da mulher a partir dessa problemática. Assim como a classe ${ }^{2}$, o gênero passa a ser também uma categoria analítica do pensamento científico, que traz novas abordagens e redimensiona os estudos sobre a mulher.

Nas universidades, esses estudos passaram a fazer veladas críticas à ciência rejeitando seu papel de neutralidade e objetividade, na qual "a positividade e o funcionalismo eram a prática comum em pesquisas nas universidades brasileiras até meados de 1985" (BRUSCHINI, 1992, p.296). Essas críticas partem de análises que apontam que nas instituições científicas foi criada uma cultura de gênero, que interditou o acesso das mulheres à ciência, da mesma forma que foi estabelecida uma cultura marcada pelas relações de classe, que distanciou o proletariado dos meios de produção que ele próprio produziu.
De certo modo, o que tem imperado nos estudos em nossas universidades, e em particular, nas universidades maranhenses, é a cultura do masculino, o que pode ser constatado pelas pesquisas sobre a temática do trabalho. A captação dos dados nesse tipo de estudo levam em conta, quase sempre, a regularidade do trabalho, a continuidade, a integralidade e a remuneração formal, segundo regras da economia capitalista. Assim, o trabalho feminino, que em geral se caracteriza pelo inverso, ou seja, é descontínuo, irregular, remunerado informalmente, muitas vezes não remunerado, tem sido ocultado pelos dados, fazendo com que as mulheres apareçam como não trabalhadoras, como não cidadãs, reforçando a ideologia dominante de que o trabalho feminino não é representativo, e por não ser representativo não é relevante.

Podemos citar como exemplo, o caso das trabalhadoras rurais, que só recentemente passaram a ser reconhecidas como trabalhadoras. Anteriormente essa categoria era considerada exclusivamente masculina, embora as mulheres, desde tempos imemoriais, tenham no cuidado com a terra uma de suas principais atividades econômicas que garantia o sustento da família. O mesmo ocorre com o trabalho doméstico, que por constituir uma atividade realizada quase que exclusivamente por mulheres, "não tem sido contabilizado como uma atividade econômica”(BRUSCHINI, 1992, p.296).

Como se vê, os dados ocultam questões importantes do trabalho feminino, visto que não levam em conta a dupla jornada de trabalho, nem a importância e necessidade dos cuidados das crianças para a preservação e continuidade da espécie. Para Passos (1997, p.27), a ruptura com

\footnotetext{
2 "A classe social é uma categoria histórica. Por não ser imutável no tempo, ela forma-se, desenvolve-se e modifica-se a medida que sociedade vai se transformando. Para Stevenhagen (1977, p.290), as lutas e os conflitos entre as classes são a expressão das contradições internas de sistemas sócio-econômicos determinados. A contradição principal que constitui 0 motor fundamental das lutas de classes é a contradição entre as forças de produção e as relações de produção... A classe dominante, que detém o poder e os meios de produção, representa as relações de produção estabelecidas na sociedade; e a classe dominada, cujo trabalho é apropriado pela outra, representa as novas forças de produção, que mais cedo ou mais tarde, entram em contradição com esse sistema de relações. Foi assim que Marx e Engels puderam dizer que a história da humanidade tem sido a história das lutas de classe".
} 
o modelo cognitivo racionalista tende a fugir das categorias universais e abstratas, que estruturam o conhecimento, incluindo novas categorias de produção do saber até então rechaçadas e consideradas atípicas ou excepcionais; aproximar a teoria da prática e romper com essas categorias dentro desse universo de dominação que vivenciamos nas universidades tem sido a marca dos estudos de gênero. São esses estudos que possibilitaram a ampliação e amadurecimento de reflexões sobre a mulher, responderam algumas questões levantadas no discurso feminista, e foram imprescindíveis na luta para ampliação dos direitos femininos.

\section{O PRO FISSSIONAL DA I N F ORM A ÇÃ O E AS Q U ESTÕ ES DE GÊ N ER O}

Pesquisas sobre mulher e gênero na Biblioteconomia são ainda em número bastante limitados, o que torna a discussão quase sempre difícil, já que as profissionais da informação, em geral, não relacionam a desvalorização social da profissão com o fato dela ser uma categoria predominantemente feminina. Este domínio, entretanto, não é criticamente analisado pelos profissionais da área que ainda não se deram conta das relações de gênero que estão impregnadas na sociedade e que, tal como as relações de classe e etnias, precisam ser revistas, estudadas e incorporadas nos conteúdos dos programas dos Cursos de Biblioteconomia, para que se possa questionar a realidade buscando uma saída para transformá-la.
Se a Biblioteconomia, enquanto ciência, prepara profissionais para o mercado de trabalho, imbuída da sistematização e disseminação do conhecimento produzido é impossível, portanto, pensar no mercado de trabalho sem analisar a sociedade que demanda para esse mercado, ou seja, uma sociedade historicamente demarcada por relações de classe, de gênero e de raça. Essa sociedade tem favorecido as profissões predominantemente masculinas, consideradas de elite, com exclusão do gênero feminino.

Estudos feitos pelo Departamento Intersindical de Estudos Estatísticos e Social Econômico apontam que é cada vez maior a entrada de mulheres no mercado de trabalho em torno de $40,3 \%$ - entretanto, $65 \%$ delas são empregadas domésticas. Por outro lado, quando se parte para análise das chamadas profissões liberais, percebemos que, embora os cursos superiores tenham sido interditados às mulheres por muito tempo ${ }^{3}$, hoje elas se constituem maioria na maior parte das universidades brasileiras ${ }^{4}$.

A entrada das mulheres nos cursos superiores acelerava-se à medida em que avançava a industrialização no País e à medida em que a ação do movimento sufragista pressionava, exigindo além do voto, o acesso a educação e ao trabalho, colocando em questão o conservadorismo da sociedade patriarcal que negava à mulher esses direitos. Ao entrar nas universidades ela percebe, entretanto, que as escolhas pelas chamadas profissões liberais, vão sendo determinadas por relações de gênero, já que como afirmam Nascimento et al. (1997, p.167), a maioria das mulheres, ao buscarem a profissionalização nas universidades, o faz

\footnotetext{
30 governo brasileiro abre as porta do ensino superior às mulheres em 1887 depois de muitas pressões do movimento feminista, que teve como precursora N ísia Floresta. "Mesmo com os cursos superiores abertos às mulheres, somente uma minoria conseguia al cançá-los. Em parte, o problema se dava porque os melhores colégios públicos só aceitavam pessoas do sexo masculino... " (ABREALAS, [2000], p.27).

${ }^{4} \mathrm{Ao}$ analisar a situação da mulher nas universidades do N orte e do N ordeste, Passos apresenta um quadro bastante positivo. Em todas as universidades estudadas (do N orte e do N ordeste), em termos absolutos as mulheres constituem maioria nos cursos superiores. Conforme declaração do Pró - Reitor da Universidade de São Paulo, 500 dos 1600 cursos de pós-graduação existente no Brasil estão na USP. Dos/as 18.500 alunos/as matriculados/as nos cursos de mestrado e de doutorado nessa instituição mais de 50\%, são mulheres (DAUCH, 2002).
} 
privilegiando as áreas de educação, saúde e ciências sociais. São crescentes, portanto, o predomínio das mulheres nos cursos de psicologia, farmácia, nutrição. A essas áreas somamse as profissões tradicionalmente reconhecidas como femininas: professora, enfermeira, assistente social e bibliotecária. A Tabela 1 ilustra perfeitamente a tendência das mulheres nas chamadas profissões femininas. Percebe-se que todas elas enfrentam dificuldades para imporemse no mundo competitivo, que é marca das sociedades capitalistas em cujo mercado a distribuição de papéis e funções especializadas são cada vez mais determinadas pela estrutura da desigualdade.

Ao questionar o que tem influenciado as escolhas profissionais das mulheres os autores afirmam que:

Tais determinações têm raízes não na "vocação ao servir", mas, sobretudo na possibilidade de desenvolver uma profissão menos competitiva, aliada a secundarização do prestígio social e econômico. Em relação aos homens parece ocorrer o inverso: a competitividade e as vantagens econômicas parecem ser a mola propulsora. É importante ressaltar que tais idéias são representações sociais, logo são constru- ções e não decorrências de natureza biológica, ou seja, mulheres não escolhem fazer esta ou aquela profissão pelo seu dom natural de servir, mas sim, pela representação que tem de si e da profissão e ainda pelas condições objetivas para exercê-la (NASCIMENTO et al., 1997).

É evidente que as profissões ditas femininas têm, ao longo da história, enfrentado dificuldades para se impor. As enfermeiras, as assistentes sociais e as bibliotecárias e outras profissões caracterizadamente femininas tem que provar permanentemente que são competentes para inserir-se nesse mercado desigual. E esse mercado é marca principal das sociedades de classe que têm na distribuição de riqueza, poder e conhecimento, fatores que contribuem substancialmente para uma distribuição desigual de competências e recompensas, assim como para a hierarquização do poder.

Falar de profissionalização hoje está intimamente ligado com as dimensões da desigualdade em relação às condições econômicas e ao poder. Nessa perspectiva status é essencial; e a profissionalização não é colocada a serviço de uma coletividade e sim de uma minoria, como forma de prestígio individual. Talvez por essa razão, a profissão de bibliotecária/o

Tabela 1. Demonstrativo de $\mathrm{n}^{\circ}$ de candidatos inscritos e a relação candidato vagas (por sexo) nos vestibulares - 1994

\begin{tabular}{|c|c|c|c|c|c|c|}
\hline \multirow[t]{2}{*}{ Área/Curso } & \multicolumn{2}{|c|}{ Candidatos } & \multirow[t]{2}{*}{ Total } & \multirow[t]{2}{*}{ Vagas } & \multicolumn{2}{|c|}{$\mathrm{n}$ ㅇ Candidato/sobre totais } \\
\hline & Homem & Mulher & & & Homem & Mulher \\
\hline Enfermagem & 62 & 454 & 516 & 56 & 1,1 & 8,1 \\
\hline Ciências Sociais & 35 & 108 & 143 & 33 & 1,1 & 3,3 \\
\hline Comunicação Social & 54 & 182 & 236 & 30 & 1,8 & 6,0 \\
\hline Biblioteconomia & 22 & 138 & 160 & 44 & 0,5 & 3,1 \\
\hline Educação Artística & 57 & 271 & 238 & 70 & 0,8 & 3,9 \\
\hline Pedagogia & 21 & 137 & 158 & 35 & 0,6 & 3,9 \\
\hline Serviço Social & 70 & 287 & 337 & 30 & 0,2 & 9,0 \\
\hline Psicologia Social & 14 & 630 & 616 & 70 & 2,3 & 9,6 \\
\hline
\end{tabular}

Fonte: NASCIMENTO et al., (1997). 
continue sob o domínio das mulheres, embora nos últimos anos perceba-se um aumento expressivo do sexo masculino no Curso de Biblioteconomia. Na década de 80, a presença de homens no curso era sempre na proporção de $100 \times 1$, após 20 anos percebe-se um aumento, são 100 mulheres $x$ cinco homens em média ${ }^{5}$. Olinto $(1997$, p.2) ao estudar as profissões femininas, considera que a Biblioteconomia enquadra-se nos níveis máxima ou extrema feminização, que inclui profissões com percentual de mulheres acima de $80 \%$. A autora enfatiza ainda que "a feminização também é característica da pós-graduação em Ciência da Informação. Uma análise feita sobre a evolução do perfil de gênero no mestrado do IBICT indica que, no período de 1970 a 1994, $83,4 \%$ dos/as mestres/as são mulheres". (OLINTO,1997, p.2).

Embora haja uma nova tendência vislumbrando mudanças, Olinto considera que isso não chega a refletir em um distanciamento, uma vez que o número de homens que se interessam pelo curso ainda é bem menor do que o número de mulheres; nem mesmo a desvinculação progressiva e acentuada da Ciência da Informação da Biblioteconomia contribuiu para estabelecer esse processo de mudança. Dessa forma, "pode-se afirmar que tanto a Ciência da Informação quanto Biblioteconomia permanecem com altas proporções de mulheres, independentemente da vinculação forte que se estabeleceu originalmente entre ambas" (OLINTO,1997, p.2) .

Ao analisar o advento das mulheres na profissão Bibliotecária, percebemos que ao ser criado, em 1911, na Biblioteca Nacional do Rio de Janeiro, o Curso de Biblioteconomia caracterizava-se pelo cunho tecnicista, dada a influência americana e humanista, bem como, a influência francesa e exigia do/a bibliotecário/a uma amplitude de conhecimentos teológicos, filosóficos, literários, artísticos e científicos e uma imagem polida e terna para com seus visitantes.

A exigência, portanto pelos conhecimentos teológicos e literários justificou-se pelo grande número de padres nas bibliotecas da Idade Média. Já no século XIX e em parte do século XX quem domina as bibliotecas são os intelectuais, que são ao mesmo tempo, escritores, e organizadores do saber ${ }^{6}$. As mulheres só começaram a dominar essa área no século $X X$, e de forma mais significativa a partir das décadas de 50 e 60, conforme dados colhidos em estudo de Castro (1997).

Antes de refletir sobre a entrada das mulheres na Biblioteconomia, vale a pena enfatizar que as mulheres somente começam a ocupar espaços no mercado de trabalho a partir dos séculos XVIII e XIX, ainda marcado por profundos preconceitos e discriminações.

Com a entrada feminina no mundo do capital, há também toda uma preocupação com a sua profissionalização e com suas escolhas. Logicamente que, se são as mulheres que maternam, que cuidam dos filhos, do marido, da casa, dos doentes e das hortas, o sistema capitalista tinha, portanto, que engajá-las em profissões afinadas com essas tarefas. Daí que em nível do senso comum, vão se justificando suas escolhas por: magistério, enfermagem, nutrição, biblioteconomia, que de alguma forma são extensões das atividades domésticas.

A entrada das mulheres nos Cursos de Biblioteconomia dá-se no final da década de vinte, sendo Adelpha Figueiredo a pioneira. Ela recebeu

\footnotetext{
5 Dados referentes ao Curso de Biblioteconomia da Universidade Federal do Maranhão.

6 O primeiro concurso para bibliotecário realizado pela Biblioteca Nacional no Rio de Janeiro em 1879, teve como concorrentes Capistrano de Abreu, historiador e jornalista, que obteve o primeiro lugar; Misael Pereira Pena, bacharel, e Antonio Pereira de Melo Moraes. A Biblioteca Nacional, principal instituição do país na área de Biblioteconomia, desde a sua criação, foi dirigida por intelectuais, homens. Somente no final da década de setenta ela foi dirigida por uma mulher, esta reconhecida pela competência técnica.
} 
os primeiros conhecimentos de Ms Dorothy Murriel Gropp que veio ao Brasil contratada para organizar o acervo do Instituto MacKenzie, em São Paulo, e para ministrar um curso Elementar de Biblioteconomia para funcionários da $\mathrm{Bi}$ blioteca e de outras instituições do Estado, do qual participou Adelpha Figueiredo. "Após o curso, Adelpha foi contemplada com uma bolsa de estudos nos Estados Unidos, oferecidas anualmente a mulheres latino-americanas" (CASTRO, 1997, p. 48). A institucionalização dos Cursos de Biblioteconomia no país coincide com a inserção das mulheres que o procuram, dada a facilidade de ingresso nesses cursos, já que grande parte deles eram oferecidos em turnos matutinos, recomendado, portanto, para "moças de boa família".

A trajetória desses Cursos é marcada nos seus primórdios pela influência das escolas francesas, o que significava uma tendência mais humanista. Entretanto, o que prevaleceu foi a influência americana, que, fundamentada no discurso tecnicista, baseada no pragmatismo, levou as escolas de biblioteconomia a adotarem um ensino, cuja preocupação era a técnica em detrimento de um ensino mais voltado para questões sociais, com conteúdos que refletissem a realidade nacional. Dessa forma, a/o bibliotecária/o desenvolveu um pensamento que, se por um lado, tinha uma preocupação com a ampliação e organização dos acervos, com o detalhamento da classificação e catalogação, com os fichários impecavelmente alfabetados, por outro lado, tentava dar uma nova dinâmica em termos de recuperação da informação, sem, entretanto, interagir com seu público real e potencial, para dimensionar a ação de seu trabalho.

A busca incessante pela perfeição fazia com que em algumas situações os/as bibliotecários/as deixassem os leitores num segundo plano. O mais importante não era a biblioteca cheia de leitores, mas, sua perfeita organização.
Com os princípios do liberalismo, amplamente divulgados no Brasil nas décadas de $30 \mathrm{e}$ 40 , novas demandas sociais demarcam as exigências da sociedade, a qual passa a exigir das/os bibliotecárias/os um novo posicionamento, frente a uma população cada vez mais exigente de qualidade de serviços. A informação passa a ser encarada como um dos fatores primordiais para favorecer mudanças, sendo exigido, portanto, um novo perfil para os profissionais da informação.

Se considerarmos que as mulheres brasileiras, até o início do século, precisavam da autorização dos maridos para assumir qualquer atividade profissional remunerada e que apenas em 1932 passaram á categoria de cidadãs, com direito ao voto, justifica-se, portanto, a sua tímida inserção na vida pública. Essa pouca inserção é fruto dos condicionamentos da educação diferenciada, que educa meninas como seres passivos e submissos e meninos como seres agressivos e dominadores, "tendo na família, na escola e na sociedade os agentes principais desses condicionamentos" (BELOTTI, 1987, p. 9). Nos últimos anos, foram significativos os avanços obtidos pelas mulheres. Esses avanços vão desde a luta pelo sufrágio universal, conquistado em 1932, o acesso a educação e ao trabalho, até a luta pela anistia, pelas diretas já e por uma maior participação nas instâncias de poder. Conquistas que permitiram que as mulheres passassem a ser vistas como cidadãs e como sujeitos autônomos.

A exemplo da grande maioria das mulheres, as bibliotecárias também passaram pelo mesmo processo de domesticação que, ao educar meninas de forma diferenciada, fizeram-nas assumirem papéis que as inferiorizam e a fazerem escolhas profissionais, baseadas em relações de gênero, portanto, hierarquizadas. Enquanto os meninos são educados para atitudes mais desprendidas, desafiantes, arrojadas e que, por isso, são mais valorizados nas suas escolhas. Meninas são estimuladas a 
buscarem profissões que "não dependem de raciocínio" afirma BELOTTI (1987).

Nas décadas de 50 e até bem recentemente a imagem que se tinha do curso de Biblioteconomia era a mesma de Pedagogia, ambos conhecidos como cursos "espera marido". Na visão de Barros apud Castro (1997), essa imagem refletia a alienação das alunas, grande parte de elite. Ao ser questionada sobre o sentido do espera marido, Barros apud Castro (1997) enfatiza que quem fazia biblioteconomia, de certa maneira o fazia dado o curso ser mais curto (três anos), o que facilitava a profissionalização das jovens, que naquele período se casavam mais cedo. Por outro lado a facilidade de entrar no mercado de trabalho também era um fator importante na decisão e escolha da profissão.

As profissões, de uma forma geral, possuem valores diferentes no mercado de trabalho, que podem ser avaliados de acordo com o salário médio ou pelo prestígio concedido pela sociedade. Salário e prestígio refletem de certa maneira o investimento médio dado em educação (OLINTO, 1997). Nas profissões femininas, entretanto, há uma tendência à desvalorização, independentemente do tempo médio de dedicação aos cursos de graduação. Essa desvalorização, segundo a autora, é reconhecida como aspecto estrutural de segregação ocupacional da mulher, direcionando sua escolha para esse tipo de profissão. A biblioteconomia enquadrase perfeitamente nesse fenômeno.

A segregação dos/as bibliotecários/as é visível quando se trata de analisar sua imagem construída ao longo de sua trajetória. Sua opção pelos processos técnicos está de certa maneira relacionada à pouca reflexão teórica. Para Castro (1997, p. 110), "o motivo da despro-porção entre o saber e o fazer biblioteconômico estaria no modo como a profissão é concebida, uma atividade de apoio, uma técnica e não um campo de saber". O autor enfatiza ainda que "o isolamento do/a bibliotecário/a parece que está no modo como se comporta na sua cotidianidade, escondendo-se nas saletas das bibliotecas, por detrás das técnicas ou por mera atitude de fuga, porque ele/a está consciente de seu pouco preparo" (CASTRO, 1997).

Ao analisar a atuação do/a bibliotecário/a no discurso publicado na Imprensa Periódica nos anos cinqüenta Castro (1997) alertava para o fato de que alguns cientistas exigiam a presença de bibliotecários/as nos locais onde realizavam pesquisas científicas; outros, entretanto, consideravam o bibliotecário/a como persona non grata, por desconhecerem seus méritos. Mesmo aqueles que reconheciam sua importância o viam como um auxiliar do cientista, apto a Ihes disponibilizar toda as informações possíveis, reduzindo assim suas funções a de mero organizador das informações.

\section{O N C L U S Ã O}

Essas análises permitem-nos refletir sobre a feminização da Biblioteconomia dando-nos alguns caminhos para compreendermos como foram construídos os mecanismos sobre os quais estão plantadas suas desvalorização. Por meio dos estudos de gênero é possível compreender como se dão os processos que têm, historicamente, submetido a mulher às posições de inferioridade. Por outro lado, é preciso que a esses estudos sejam incorporadas as análises sobre as estruturas das classes sociais, largamente difundidas nos estudos marxistas, que, ao abordarem as relações sociais no Estado capitalista, subsidiam as análises sobre relações de produção, que são marcas comuns das desigualdades que fundamentam e referenciam as sociedades de mercado. Os estudos marxistas nos ajudam a entender a natureza íntima do capitalismo "e a lógica de seu desenvolvimento, revolucionando permanentemente as condições de produção, especialmente através do aumento da 
produtividade, o que por sua vez determina a proletarização da maior parte da humanidade" afirma Moraes (2000). Se essa é uma questão amplamente discutida nas diversas áreas das ciências sociais; na Biblioteconomia, ela é ainda uma questão tratada com reservas.

A construção de uma nova identidade na biblioteconomia está na revisão e no questionamento do papel do/a bibliotecário/a, no repensar a profissão e as unidades de informação e em como estas têm influenciado efetivamente a luta do povo brasileiro por igualdade de condições materiais e culturais de vida e liberdade. A construção de uma nova identidade, portanto, significa redimensionar a Biblioteconomia, buscando uma práxis social transformadora, vinculada a uma profunda revisão de seus currículos, de forma a articular sua ação pedagógica com sua ação política, tendo como princípio o combate à ignorância e a alienação dentro de seus próprios quadros.

Dessa forma, os profissionais poderão constituir-se como sujeitos e, como tais, poderão contribuir para transformar as relações sociais, que têm na informação um mecanismo de mudança social e política. A Biblioteconomia não avançará para ser práxis social enquanto não se desvincular dos interesses científicos e tecnológicos da classe hegemônica. Ela precisa redimensionar "seus objetivos para a ampliação dialética da difusão/criação do conhecimento para o conjunto da sociedade, fazendo da própria difusão um momento da criação"(CYSNE, 1993, p.54).

Essa situação poderá modificar-se quando o/a bibliotecário/a rearticular o eixo de sua ação com uma práxis social, "assumindo uma postura crítica do papel da informação, dos sujeitos, do mundo e de si mesmo" CYSNE (1993, p.78). Essa postura crítica de si mesmo significa para as/os bibliotecárias/os rever sua trajetória enquanto gênero, bem como as dificuldades históricas que as mulheres têm enfrentado para galgar espaços, antes não ousados, que as colocam hoje em relativa igualdade com o sexo oposto.

Essa revisão de papéis, esse encontro de si mesma e com outras profissões dará à Bibliotecária um amadurecimento enquanto profissional e enquanto cidadã. Na medida que a consciência do gênero aflora, acreditamos que se prenunciará o nascimento de uma profissional mais comprometida e mais consciente do projeto político da sociedade, no qual alguns setores da Biblioteconomia estão imbuídos. Na Biblioteconomia, esse projeto baseia-se na igualdade e na socialização da informação, que "predispõe a superação das dificuldades pessoais e sociais, que prejudicam ou desfavorecem os indivíduos" (CAPPELLIN, 1996, p.169) e constituem-se ações positivas que podem modificar e superar essas diferenças e desigualdades sociais. É certo que essas ações positivas têm que vir com reflexões que ajudem no amadurecimento das relações pessoais e profissionais, para que se encontre o amadurecimento necessário às profissões. Um dos pontos a refletir é o reencontro com as profissões consideradas femininas, para reconhecermos com que bagagem, saberes e práticas elas têm contribuído em relação ao crescimento da humanidade e do trabalho.

A construção de uma nova identidade para a Biblioteconomia e para os/as bibliotecários, portanto, está na busca do reequilíbrio entre as origens da profissão e sua ação política.

As reflexões aqui levantadas são frutos de inquietações de longos anos, da militância no movimento feminista e bibliotecário e de estudos desenvolvidos no mestrado e mais recentemente no doutorado. A falta de eco nesses estudos na Biblioteconomia se, em alguns momentos causaram desânimo, contribuindo para um quase distanciamento da área, em vários outros momentos, mesmo rechaçado, levantamos polêmicas que, ao causar indignação, superava a indiferença. Hoje mais digerível, acreditamos ser possível fazer dessa 
discussão um ponto importante nas reflexões que ora se fazem nos cursos de biblioteconomia, que buscam saídas para seu pouco reconhecimento e, em algumas situações seu quase desaparecimento. Ao compreender os mecanismos que em geral limitam ou desvalorizam as profissões femininas, que são similares ao/a bibliotecário/a, esse/a poderá instrumentalizarse com recursos para combater os estereótipos, fruto da cultura de gênero, que se caracteriza por produzir vantagens para os homens.

Em estudos realizados nos Estados Unidos sobre a imagem do homem na profissão de bibliotecário, sugerem que:

Para se distanciar do estereótipo feminino, os homens procuram se destacar das mulheres mostrando, desde o início da carreira, o seu interesse por tarefas administrativas e se afastando das tarefas técnicas. Da mesma forma, as tarefas que envolvem o uso de tecnologia moderna tenderiam a ser mais disputadas pelos homens. Essa dinâmica também ajudaria a explicar o diferencial de salários entre os sexos na profissão (OLINTO, 1997, p.7).

Se esses pontos apresentados por Olinto não explicam no seu todo, entretanto abrem caminhos para novas reflexões. É nosso desejo que estas reflexões tenham ressonância na Biblioteconomia, para que seja possível, em futuro próximo, bibliotecárias e bibliotecários

\section{REFERÊ N CIAS}

ARENDT, H. A Condição Humana. Rio de Janeiro: Forense Universitária, salamandra, São Paulo: EDUSP, 1981. Cap. 2, p.31-89: As esferas públicas e privadas.

BELOTTI, E.G. Educar para submissão: o descondicionamento da mulher. 6.ed. Petrópolis: Vozes, 1987. $164 \mathrm{p}$. estarem compartilhando um novo momento político, pautado em um debate, sobre as mudanças que têm se efetivado no país, no que se refere à revisão de papéis masculinos e femininos, trazendo essa discussão para o curso, de forma a rever suas linhas de pensamento e sua práxis social, na qual a mulher na biblioteconomia é sujeito.

Se há uma década era difícil vislumbrar mulheres assumindo funções, antes consideradas de total domínio dos homens, a exemplo das engenharias ou mesmo as ligadas ao legislativo e executivo, hoje, as mulheres desafiam posturas conservadoras ao assumirem câmaras, governos estaduais e municipais, tribunais, delegacias de polícia, etc. Ao assumir essas novas funções, as mulheres têm levado à sociedade uma revisão de determinados conceitos e preconceitos, frutos de culturas patriarcais.

Considero que os debates, que têm se processado nos últimos anos, no sentido de uma revisão crítica da Biblioteconomia, assim como, uma revisão do objeto e objetivos de seu trabalho, proposto por diversos autores, a exemplo de Cysne, MOSTAFA, têm alertado os pro-fissionais para a busca de novas respostas para a crise que a categoria vem enfrentando nas últimas décadas. Da mesma forma, considero que trabalhar a questão de gênero como categoria de análise nos cursos de Biblioteconomia significa redimensionar o papel da bibliotecária, contribuindo para uma revisão crítica de seu trabalho enquanto profissional e enquanto cidadã.

BRUSCHINI C. Uso de abordagens quantitativas em pesquisa sobre relações de gênero. In: COSTA, A O; MUSCHINI, C. Uma questão de gênero. Rio de Janeiro: Rosa dos Tempos, 1992. p. 289-299.

CAPPELIN, P. A valorização do trabalho feminino: contextualizando as ações positivas. Estudos Feministas. v.4, n.1, p.158-170, 1996. 
CARVALHO, G. V. Biblioteca Nacional: 1870-1990: Biografia. Rio de Janeiro: Irradicação Cultural, 1994.

CASTRO, C. Um olhar distanciado para os velhos objetos. 1997. 342f. Tese (Doutorado em Educação) - Universidade São Paulo, 1997.

CYSNE, F.P. Biblioteconomia dimensão social e educativa. Fortaleza: Ed. UFC, 1993. 145 p.

LEGISLATIVO Federal discute perfil da mulher brasileira: IBGE divulga aspectos da população feminina e sua participação no mercado de trabalho. Jornal CFEMEA, v.10, n.111, p.6-7, 2002.

MACHADO, L.Z. Feminismo, academia e interdisciplinaridade . In: COSTA, A.O.; BRUSCHINI, C. Uma questão de gênero. Rio de Janeiro: Rosa dos Tempos; 1992. p.24-37.

NASCIMENTO, S.M.; FERREIRA, M.M.; BATISTA, I. C. Gênero e universidade: uma abordagem na UFMA. In: Passos, E. (Org.) Um mundo dividido: o gênero nas universidades do Norte e Nordeste. Salvador: UFBA, 1997. p.163-186.

OLINTO, G. Biblioteconomia e profissões femininas. In: CONGRESSO BRASILEIRO DE BIBLIOTECONOMIAE DOCUMENTAÇÃO, 18.,1997. São Luís. Anais C/N. São Luís, 1997.

PASSOS, E. (Org.) Um mundo dividido: o gênero nas universidades do Norte e Nordeste. Salvador: UFBA, 1997. 286 p. As políticas e os saberes: a construção do gênero nas universidades do Norte e Nordeste e as repercussões nos campos social e político. In: FERREIRA, M. Álvares, M. L. M., Santos, E. F., (Orgs.) Os poderes e os saberes das mulheres: a construção do gênero. São Luís: EDUMA, 2001. p.21-54.

SAFIOTTI, H. Violência doméstica: questão de polícia e da sociedade: projeto de pesquisa, [s.l.: s.n.], 1994. 14p. Mimeografado.

\section{B I B LIO GRAFIACO N S LTA DA}

ABREALAS: o feminismo na virada do século XIX/XX. Rio de Janeiro: REDEH, 2000. 55p.

ALVES, B.M. Ideologia e feminismo: a luta da mulher pelo voto no Brasil. Petrópolis: Vozes, 1980. $197 \mathrm{p}$.

BARBOSA, M.L.O. A sociologia das profissões: em torno da legitimidade de um objeto. BIB, Boletim Informativo e Biográfico de Ciências Sociais, Rio de Janeiro, n.36, p.3-30, 1993.

BERTO, R. M. V. S. Carreira do futuro ou o futuro da carreira. Transinformação, Campinas, v.8, n.1 p.144-157, 1996.

COSTA, A.O. Os estudos da mulher no Brasil ou a estratégia da corda bamba. Estudos Feministas, Rio de Janeiro, jul./dez. p.101-409, 1994. Edição Especial.

COSTA, A.O.; BARROSO, C.; SARTI, C. Pesquisa sobre mulher no Brasil do limbo ao gueto? Caderno de Pesquisa, São Paulo, n.54, p.5-15, 1985.

DANTAS, M. Valor-trabalho e valor-informação. Transinformação, Campinas v.8, n.1, p.55-88, 1996.
DAUCH, K. Alta qualificação credencia brasileiras ao sucesso. Disponível em: < [http://www.estado.on. br/edição mulher/trabalho/pos.html]>. Acesso em: set. 2002.

DIEESE. A Situação do Trabalho no Brasil. São Paulo: DIEESE, 2001. 352p.

FERREIRA, M. M. Gênero como categoria de análise na biblioteconomia. In: CONGRESSO BRASILEIRO DE BIBLIOTECONOMIA E DOCUMENTAÇÃO, 18., 1997, São Luís. Anais eletrônico. São Luís, 1997.

FERREIRA, M. (Org.) Mulher, gênero e políticas públicas. São Luís: Grupo de Mulheres da llha, REDOR, 1999. 136p.

FERREIRA, M.M. Pesquisando mulher e gênero na Universidade Federal do Maranhão: 1975 - 1995. In: ÁLVARES, M.L.M.; SANTOS, E.F. Desafios de identidade: espaço - tempo de mulher. Belém: UFPA/GEPEM, 1997. 333-354.

FERREIRA, M.M. Mulher e participação política no Maranhão. In: FERREIRA, M., ÁLVARES, M.L.M.; SANTOS, E.F. Os poderes e os saberes das mulheres: a construção do gênero. São Luís: EDUMA, 2001. p.103-122. 
GUIMARÃES, J.A.C. Divulgação profissional: uma proposta pedagógica como suporte ao desenvolvimento da profissão bibliotecária no Brasil. Transinformação, v.6, n.1/2/3, p.43-59, 1994.

LAVINAS, L. Aumentando a competividade das mulheres no mercado de trabalho. Estudos Feministas, v.4, n.1, p.171-182, 1996.

LIMA, N.R.L.B. Mulher e Ciência: a hegemonia do código patriarcal. Seminário Mulher e Ciência. Maceió, 1989. p.17-31.

MARCHIORI, P.Z. Bibliotecários, jornalistas e informáticos: ocupação de posições relativas no campo de atividades de informação. Transiformação. v.8 n.1, p.89-111, 1996.

MARENGO, L. A sociedade de informação e o mercado de trabalho. Transinformação. v. 8, n.1, p.112-143, 1996.

MORAES, M.L.Q. Marxismo e feminismo: afinidades e diferenças. Crítica Marxista, n.11, p.89-97, 2000.
PASSOS, E. (Org.) Um mundo dividido: o gênero nas universidades do Norte e Nordeste. Salvador: UFBA, 1997. $286 \mathrm{p}$.

STAVENHAGEN, R. Classes sociais e estratificação social. In: FORACCHI, M.M., MARTINS, J.S. Sociologia e sociedade: leituras de introdução à sociologia. Rio de Janeiro: Livros Técnico e Científico, 1977. p.282-296.

SCHIENBINGER, Londa. O Feminismo mudou a ciência? Bauru: EDUSC, 2001.382p.

SEXO no trabalho. Tradução de Sueli Cassal. Rio de Janeiro: Paz e Terra, 1987.193p.

TOSTANO, M.; GOLDENBERG, M. A Revolução das mulheres: um balanço do feminismo no Brasil. Rio de Janeiro. Revan, 1992. 117 p.

VENTURINI, G.; RECÁMEN, M. Afinal o que querem as mulheres. Teoria e Debate, v.15, n.50, p.44-47, 2002. 
